удК 347.44

\author{
М. А. Гребенюк \\ Байкальский государственный университет, \\ г. Иркутск, Российская Федерация
}

\title{
О ПРАВОВОЙ ПРИРОДЕ КОРПОРАТИВНОГО ДОГОВОРА
}

\begin{abstract}
АНнотАЦия. В настоящее время вопрос о правовой природе корпоративного договора является дискуссионным. Несмотря на многочисленные предложения, выработанные юридической наукой по данному вопросу, ни одно из них не может быть признано господствующим. В статье предпринята попытка установить место корпоративного договора в отечественной системе гражданско-правовых договоров. В целях решения этого вопроса исследованы основные существующие в науке корпоративного права взгляды на правовую природу корпоративных соглашений, дана их авторская оценка. Особое внимание в статье уделено изучению критериев выделения типа договоров о совместной деятельности. Сделан вывод о том, что по совокупности своих признаков, а также правовой цели корпоративный договор является одним из видов договоров о совместной деятельности. Также приведены доказательства того, что корпоративный договор по своей природе отличен от договора простого товарищества. На основании сделанных выводов обосновано предложение о внесении изменений в главу 55 Гражданского кодекса Российской Федерации.
\end{abstract}

КЛЮЧЕВЫЕ СЛОВА. Корпоративный договор; правовая природа корпоративного договора; договор о совместной деятельности; решение собрания.

ИНФОРМАЦИЯ О СТАТЬЕ. Дата поступления 31 июля 2017 г.; дата принятия к печати 11 октября 2017 г.; дата онлайн-размещения 25 октября 2017 г.

M. A. Grebenyuk Baikal State University, Irkutsk, Russian Federation

\section{ON LEGAL NATURE OF CORPORATE CONTRACT}

\begin{abstract}
Currently, the issue of legal nature of the corporate contract remains open to discussion. Despite the numerous proposals worked out by the legal science on this issue, none of them can be recognized as prevailing. The article attempts to determine the place of the corporate contract in the national system of civil-legal contracts. In order to solve this issue, it studies the main views of the corporate contract legal nature, that exist in the corporate law science, and gives the author's assessment. The article pays a special attention to investigating the criteria of identifying the type of joint activities agreements. It makes a conclusion that both in the set of its attributes and its legal purpose the corporate contract is one of the types of the agreements on joint activities. It brings forth a proof of the fact that the corporate contract in its nature differs from the single partnership agreement. On the basis of the conclusions drawn, the article substantiates a proposal to amend Chapter 55 of the Civil Code of the Russian Federation.
\end{abstract}

KEYWORDS. Corporate contract; legal nature of corporate contract; agreement on joint activities; decision of the meeting.

ARTICLE INFO. Received July 31, 2017; accepted October 11, 2017; available online October 25, 2017.

Практически ни одно научное исследование, посвященное изучению корпоративного договора, не обходится без рассмотрения одного из самых обсуждаемых вопросов его правового регулирования — вопроса о правовой природе. Прежде чем перейти к его исследованию в настоящей работе следует установить содержание понятия «правовая природа». По нашему мнению, его наиболее емкое определение было дано профессором С. С. Алексеевым, который рассматривал правовую

\section{Baikal Research Journal}


природу как «юридическую характеристику правового явления, выражающую его специфику, место и функции среди других правовых явлений в соответствии с его социальной природой» [1, с. 227].

Что касается определения правовой природы корпоративных соглашений, необходимо отметить, что еще до появления в 2014 году в Гражданском кодексе Российской Федерации ${ }^{1}$ (далее - ГК РФ) норм о корпоративном договоре общепризнанным [2, с. 106; 3, с. 7] в науке и на практике было мнение о том, что корпоративное соглашение является гражданско-правовым договором.

Еще в 2008 году авторы Концепции развития законодательства о юридических лицах ${ }^{2}$ указывали, что необходимо четко определить обязательственно-правовую природу корпоративных соглашений, которая исключает их действие как на третьих лиц, так и на хозяйственное общество в целом. К аналогичному выводу также пришли члены Совета при Президенте Российской Федерации по кодификации и совершенствованию гражданского законодательства при рассмотрении проекта федерального закона «О внесении изменений в Гражданский кодекс Российской Федерации и Федеральный закон «Об акционерных обществах» (в части регулирования акционерных соглашений) ${ }^{3}$ (далее - законопроект об акционерном соглашении), которые в своем экспертном заключении отметили, что «по своей правовой природе акционерное соглашение является гражданско-правовым договором ${ }^{4}$.

Непосредственный разработчик норм об акционерном соглашении - Министерство экономического развития письмом ${ }^{5}$, принятым в части регулирования института акционерных соглашений и его же информацией, разъяснило, что акционерное соглашение представляет собой гражданско-правовой договор, к которому применяется гражданское законодательство России, в том числе общие положения части первой ГК РФ о сделках, обязательственном праве и договорах.

Этой же концепции придерживалась и судебная практика 6 .

Сделанный в науке вывод однозначно следовал также из толкования статьи 321 Федерального закона от 26 декабря 1995 года № 208-Ф3 «Об акционерных обществах» (далее - Закон об АО), которая предусматривала, что заключение между акционерами соглашений не влечет возникновения обязанностей для третьих лиц и не влияет на действительность решений органов акционерного общества.

Несмотря на вышесказанное, в литературе хоть и нечасто, но высказывались мнения, отличные от общепризнанного. Так, С. А. Ломовский [4, с. 35] рассматривал акционерное соглашение в качестве источника регулирования прав и обязанностей акционеров, являющихся сторонами указанного соглашения.

Закрепление в ГК РФ правовой конструкции корпоративного договора не привело к прекращению дискуссии по данному вопросу, а напротив, способствовало появлению новых взглядов на природу корпоративного договора. В частности, в литературе [5, с. 122] было высказано мнение о том, что корпоративный договор является не договором, а решением общего собрания участников, поэтому, напри-

${ }^{1}$ Гражданский кодекс Российской Федерации (часть первая) : федер. закон от 30 нояб. 1994 г. № 51-Ф3 // Собрание законодательства Российской Федерации. 1994. № 32. Ст. 3301.

${ }^{2}$ Вестник гражданского права. 2009. Т. 9, № 2. С. 43.

${ }^{3}$ Из практики Совета по кодификации и совершенствованию гражданского законодательства при Президенте Российской Федерации // Вестник гражданского права. 2008. № 1. С. 128-154.

${ }^{4}$ Там же. С. 152.

5 О разъяснении изменений, внесенных в Федеральный закон «Об акционерных обществах" [Электронный ресурс] : письмо Минэкономразвития от 8 нояб. 2009 г. № Д06-2643 // СПС «КонсультантПлюс».

${ }^{6}$ Решение Арбитражного суда Хабаровского края от 5 нояб. 2013 г. по делу № A73-8807/2013 [Электронный ресурс] // СПС «КонсультантПлюс» ; Постановление Шестого арбитражного апелляционного суда от 14 февр. 2014 г. № 06АП-6954/2013 по делу А73-8807/2013 [Электронный ресурс] // Там же.

\section{Baikal Research Journal}

электронный научный журнал Байкальского государственного университета 
мер, недействительность корпоративного договора и иные правовые последствия его заключения необходимо определять с учетом главы 91 , а не главы 9 ГК РФ.

В другой научной работе [6, с. 24] корпоративный договор рассматривается как источник регулирования корпоративных отношений - нормодоговор локального уровня. При этом автор отмечает, что если обычный гражданско-правовой договор регулирует правоотношения между сторонами, то корпоративный договор создает норму права, регулирующую корпоративные отношения.

На наш взгляд, наличие подобных мнений в литературе объясняется особой (корпоративной) составляющей исследуемого договора, которая выражается в особом порядке осуществления сторонами договора своих прав и обязанностей. На обязательственно-корпоративный дуализм правовой природы корпоративных договоров указывали многие ученые [7, с. 38]. Еще при обсуждении законопроекта об акционерном соглашении Г. Е. Авилов отметил, что «это не обычные обязательства. Это обязательства, которые лежат в рамках корпоративных отношений. Они лежат внутри другой оболочки, внутри другой общности. И соответственно там появляются свои особенности, которых у обычных обязательств нет» ${ }^{7}$.

Несомненно, что специфику корпоративного договора, обусловленную весомой корпоративной составляющей, которой не обладают иные гражданско-правовые договоры, отрицать нельзя. Однако квалифицировать корпоративный договор в качестве источника права только на этом основании вряд ли справедливо. Будучи актом индивидуального правового регулирования, корпоративный договор направлен на удовлетворение интересов только тех участников хозяйственного общества, которые являются сторонами этого договора. Порядок осуществления корпоративных прав иными участниками хозяйственного общества, так же как и правовое положение корпорации в отношениях с третьими лицами в результате заключения корпоративных соглашений между ее отдельными участниками не изменяются. Кроме того, корпоративный договор далеко не всегда заключается между всеми участниками хозяйственного общества, чаще это происходит наоборот, поэтому говорить о кворуме, необходимости соблюдения определенной процедуры голосования и иных обстоятельствах, учитываемых при принятии решения собрания, применительно к корпоративному договору не представляется возможным.

В связи с вышеизложенным наиболее оправданным и точным с позиций системы права является мнение о том, что корпоративный договор - это гражданско-правовой договор.

Вместе с тем изучением вопроса о том, является ли корпоративный договор договором либо имеет иной правовой статус, споры о его правовой природе не ограничиваются. Ввиду того, что подавляющее большинство ученых рассматривает корпоративный договор в качестве гражданско-правового, основная дискуссия лежит в плоскости определения правового статуса корпоративного договора как одного из видов гражданско-правового.

C момента появления норм об акционерном соглашении, договоре об осуществлении прав участников общества с ограниченной ответственностью и по настоящее время в науке предпринимаются многочисленные попытки квалификации корпоративных соглашений. Рассмотрим некоторые из них.

Так, А. Бычков [8, с. 42] определял акционерное соглашение как смешанный гражданско-правовой договор в тех случаях, когда оно содержит элементы договора купли-продажи и (или) акцессорного обязательства К выводу о том, что корпоративный договор является смешанным, пришел и В. Г. Бородкин [9, c. 1], выделяя два предмета корпоративного договора: на случай установления в

${ }^{7}$ Из практики Совета по кодификации и совершенствованию гражданского законодательства при Президенте Российской Федерации // Вестник гражданского права. 2008. № 1. С. 147.

\section{Baikal Research Journal}

электронный научный журнал Байкальского государственного университета 
договоре организационных обязательств и на случай определения порядка распоряжения акциями.

Наделение корпоративного договора статусом смешанного вызывает сомнения. Следует согласиться с суждениями тех ученых [10, с. 55], которые рассматривают акцессорное обязательство не в качестве самостоятельного договора, а как зависимое от главного и возникающее на его основании обязательство. Поскольку в соответствии с пунктом 3 статьи 421 ГК РФ смешанным признается договор, в котором содержатся элементы различных договоров, предусмотренных законом или иными правовыми актами, включение акцессорного обязательства в содержание корпоративного договора свидетельствует о невозможности наделения смешанным характером договора, в составе которого оно есть.

Кроме того, далеко не каждое из заключенных корпоративных соглашений является обеспеченным или содержит условие о продаже акций или долей в уставном капитале хозяйственного общества. Однако, даже при включении таких условий в корпоративный договор на определение правовой природы обязательства данный факт не должен оказывать никакого влияния. Как отмечали М. И. Брагинский и В. В. Витрянский, «рассматривать отдельные случаи квалификации не стоит, поскольку получается, что едва ли не каждый заключенный договор смешанный, поскольку в нем присутствуют элементы различных содержащихся в законе договорных эталонов, и количество возможных сочетаний может достичь астрономической величины» $[11$, с. 330$]$.

Особого внимания заслуживает также мнение Е. Д. Суворова [12, с. 44-46], который изучая акционерное соглашение, пришел к выводу о том, что данное соглашение вообще не является видом договора. Автор объясняет это отсутствием каузы, элемент же саморегулирования, как отличительный признак договора, по мнению ученого, правовой целью не является и лежит за пределами юридической сделки. Тем самым, полагает ученый, нормы статьи 321 Закона об АО рассчитаны на любые договоры между участниками по поводу осуществления их прав, и в результате квалифицирует акционерное соглашение как специальную конструкцию с общим элементом наряду с публичным договором или договором присоединения. По мнению автора, квалификации подлежат отдельные виды корпоративных соглашений: соглашения о голосовании (непоименованные договоры), договоры о покупке или продаже акций (предварительные договоры купли-продажи под отлагательным условием), соглашения о совместном осуществлении прав (договоры о совместной деятельности).

Между тем для выделения специальной договорной конструкции необходимо, чтобы «она подлежала применению практически к любым видам договорных обязательств, которые обладают необходимым набором признаков, характерных для каждой специальной договорной конструкции» [13, с. 51]. Однако применительно к корпоративным соглашениям говорить об этом не представляется возможным. Если следовать размышлениям автора, то скорее следует рассматривать содержание статьи 321 Закона об АО, как общие требования, которым должны соответствовать заключенные по тому или иному вопросу отдельные виды акционерных соглашений (о голосовании определенным образом, о продаже акций и т.д.). Кроме того, несмотря на то, что предмет корпоративных соглашений могут составлять различные по содержанию действия, правовая цель данных соглашений всегда остается неизменной - определенный порядок осуществления корпоративных прав.

Многие ученые [14, с. 20; 9, с. 39] подчеркивают тесную связь корпоративного договора с договором простого товарищества.

\section{Baikal Research Journal}

электронный научный журнал Байкальского государственного университета 
Так, например, В. Г. Бородкин [9, с. 39] отмечает, что корпоративное соглашение может быть построено по модели договора простого товарищества, обосновывая это тем, что двое или несколько лиц (товарищей) обязуются соединить свои вклады и совместно действовать без образования юридического лица для извлечения прибыли или достижения иной цели. Аналогичного мнения придерживается также Р. В. Шмелев [15], который в качестве еще одного аргумента квалификации корпоративного договора в качестве договора простого товарищества указывает на пункт 10 статьи 672 ГК РФ, предусматривающий применение норм о корпоративном договоре к договору о создании хозяйственного общества, являющегося типичным примером договора о совместной деятельности.

Представляется, что основной причиной распространения в науке мнения о том, что корпоративный договор является по своей природе договором простого товарищества или обязательством из совместной деятельности, является обращение ученых к зарубежному опыту регулирования корпоративных соглашений. Как отмечают Д. И. Степанов, В. А. Фогель и Х.-И. Шрамм, «в немецкой литературе превалирует мнение о том, что соглашения участников представляют собой следствие развития логики гражданско-правового соглашения участников о создании общества частного права, очень схожего с российской конструкцией договора простого товарищества» $[16$, с. 50$]$. Однако, в отличие от российского законодательства, в Германии для соглашения не требуется внесение вкладов, к тому же, как отмечают немецкие юристы, не всегда соглашение участников корпоративного образования может быть подчинено правилам о совместной деятельности.

Что касается отечественного правопорядка, то из буквального толкования статьи 1041 ГК РФ следует, что договоры о совместной деятельности ограничиваются только договором простого товарищества, квалифицирующими признаками которого являются объединение вкладов, совместная деятельность, а также общая цель сторон, состоящая в достижении прибыли или любого иного не противоречащего закону результата. При этом А. Б. Савельев [17, с. 414] особо подчеркивает решающее значение двух индивидуализирующих признаков договора простого товарищества - его безусловной многосторонности и объединения имущества. Между тем заключая между собой договор, участники хозяйственного общества не вносят имущество и не объединяют вкладов, а в процессе его исполнения не создается общее имущество участников (товарищей). В связи с этим определение корпоративного договора как договора простого товарищества не представляется оправданным.

Несмотря на то, что из буквального толкования статьи 1041 ГК РФ следует, что в отечественном правопорядке договоры о совместной деятельности представлены только договором простого товарищества, перечень таких обязательств гораздо шире. В целях установления возможности отнесения корпоративного договора к договорам о совместной деятельности, представляется необходимым определить правовую природу последних. Для этого следует обратиться к системе гражданско-правовых договоров.

Договоры о совместной деятельности или общецелевые договоры как тип договоров выделяются многими учеными [18, с. 15-16], занимающимися изучением вопросов о системе гражданско-правовых договоров.

Так, М. И. Брагинский и В. В. Витрянский $[11$, с. 451] классифицировали все договоры на договоры, направленные на передачу имущества, выполнение работ, оказание услуг, учреждение различных образований, к которым и отнесли договоры о совместной деятельности.

В свою очередь, Ю. В. Романец в системе договоров выделяет группу общецелевых договоров (договоров о совместной деятельности) - договоров, направ-

\section{Baikal Research Journal}

электронный научный журнал Байкальского государственного университета 
ленных на достижение цели, единой для всех участников, к которой относит учредительные договоры и договоры простого товарищества. Основной характеристикой общецелевых договоров, по мнению ученого, являются единая цель его участников и тождественность их интересов. Рассматривая направленность договоров как системный признак их классификации, Ю. В. Романец отмечает, что «направленность обязательства выражается не в основном действии обязанного лица как таковом, а в экономическом и юридическом результатах, на достижение которых направлено это действие» [19, с. 405].

С учетом вышеизложенного имеются все основания для отнесения корпоративного договора к типу договоров о совместной деятельности. Именно общая цель и одинаковые интересы участников хозяйственных обществ, связанные с желанием достичь определенного результата голосования на общем собрании, не допустить утраты корпоративного контроля и иные подобные интересы являются предпосылками и главной причиной заключения корпоративных соглашений. Так, направленность корпоративного договора состоит не в исполнении обязанностей по голосованию определенным образом на общем собрании участников, по неотчуждению акции (доли в уставном капитале) до наступления определенных обстоятельств или совершению аналогичных действий под отлагательным условием, а в том результате (эффекте), которого достигнут стороны при выполнении условий корпоративного договора - например, в сохранении корпоративного контроля, недопущении проведения реорганизации хозяйственного общества и т.д.

В юридической литературе вопрос о видах договоров о совместной деятельности является неоднозначным. Так, например, Ю. В. Романец [19, с. 147] относит к ним договоры, направленные на создание юридического лица (учредительные договоры), и договоры, направленные на организацию совместной деятельности без образования юридического лица (договоры простого товарищества). При этом ученый отрицает существование гражданских общецелевых договоров, не требующих внесения участниками имущественных вкладов в той или иной форме.

Думается, что с этим мнением согласиться нельзя. Внесение вкладов не является главным квалифицирующим признаком общецелевых договоров и необходимым условием для достижения общей цели участников договора. Как справедливо отмечает А. Б. Савельев [17, с. 18], договор о совместной деятельности в отличие от договора простого товарищества не всегда требует объединения имущества или иных вкладов участников, которым достаточно договориться лишь о совместном достижении какой-либо цели. Типичным примером такого договора как раз и является, по нашему мнению, корпоративный договор.

В связи с этим наиболее точной и отвечающей сложившейся $\mathrm{\kappa}$ настоящему времени системе договоров о совместной деятельности считаем классификацию А. Б. Савельева [17, с. 20], который по признаку объединения вкладов выделяет следующие виды договоров о совместной деятельности: договоры, для которых объединение, как минимум, имущественных вкладов для совместной деятельности необходимо (договоры простого товарищества и учредительные договоры), и договоры, где такие вклады не обязательны (иные соглашения о совместной деятельности).

Выделение как в науке, так и в законодательстве указанных видов договоров о совместной деятельности является, по нашему мнению, предпосылкой для внесения изменений в главу 55 ГК РФ. В целях систематизации соглашений о совместной деятельности, а также установления места корпоративного договора в системе договоров целесообразно переименовать главу 55 ГК РФ, и в качестве ее отдельных параграфов предусмотреть параграфы, посвященные правовому регулированию двух основных видов договоров о совместной деятельности - договору

\section{Baikal Research Journal}

электронный научный журнал Байкальского государственного университета 
простого товарищества и корпоративному договору, нормы о которых будут применимы к любым общецелевым обязательствам: в первом случае - к договорам, для заключения которых требуется внесение имущественных вкладов, во втором случае - к договорам, для заключения которых внесение вкладов не требуется.

\section{Список использованной литературы}

1. Алексеев С. С. Общие дозволения и запреты в советском праве / С. С. Алексеев. М. : Юридическая литература, 1989. - 288 с.

2. Рублев В. В. Понятие и правовая характеристика акционерного соглашения как гражданско-правового договора, регулируемого гражданским законодательством России / В. В. Рублев // Современное право. - 2010. — № 9. - С. 102-109.

3. Сергеев А. П. Юридическая природа и использование акционерных соглашений по российскому праву / А. П. Сергеев // Корпоративный юрист. - 2007. — № 10. - С. 6-10.

4. Ломовский С. А. Новое в правовом регулировании акционерного соглашения в российском законодательстве / С. А. Ломовский // Законодательство. - 2010. — № 5. C. $34-39$.

5. Андреев В. К. Корпоративное право современной России: монография / В. К. Андреев, В. А. Лаптев. - М. : Проспект, 2016. - 240 с.

6. Лаптев В. А. Корпоративный договор в системе источников регулирования корпоративных отношений / В. А. Лаптев // Предпринимательское право. — 2016. — № 1 . C. $23-31$.

7. Шиткина И. С. Соглашения акционеров (договоры об осуществлении прав участников) как источник регламентации корпоративных отношений / И. С. Шиткина // Хозяйство и право. - 2011. - № 2. - С. 36-47.

8. Бычков А. И. Случаи, когда акционерное соглашение является смешанным договором / А. И. Бычков // Адвокатская практика. - 2011. - № 5. - С. 40-43.

9. Бородкин В. Г. Предмет и содержание корпоративного договора в России и иностранных правопорядках / В. Г. Бородкин // Право и экономика. - 2014. - № 2. - С. 39-44.

10. Гонгало Б. М. Учение об обеспечении обязательств. Вопросы теории и практики / Б. М. Гонгало. - М. : Статут, 2004. - 222 с.

11. Брагинский М. И. Договорное право. Общие положения / М. И. Брагинский, В. В. Витрянский. - 3-е изд., стер. - М. : Статут, 2001. - 848 с.

12. Суворов Е. Д. Договор об осуществлении корпоративных прав / Е. Д. Суворов // Вестник ВАС РФ. - 2011. - № 10. - С. 44-72.

13. Витрянский В. В. Система гражданско-правовых договоров в условиях реформирования гражданского законодательства / В. В. Витрянский // Вестник ВАС РФ. — 2012. № 1. - С. 26-59.

14. Гуреев В. А. Проблемы защиты прав и интересов акционеров в РФ : автореф. дис. ... канд. юрид. наук : 12.00 .03 / В. А. Гуреев. - М., 2007. - 28 с.

15. Шмелев Р. В. Корпоративный договор в гражданском праве Российской Федерации [Электронный ресурс] / Р. В. Шмелев // СПС «КонсультантПлюс» .

16. Степанов Д. И. Корпоративный договор: подходы российского и немецкого права к отдельным вопросам регулирования / Д. И. Степанов, В. А. Фогель, Х.-И. Шрамм // Вестник ВАС РФ. - 2012. - № 10. - С. 22-69.

17. Савельев А. Б. Договор простого товарищества в российском гражданском праве : автореф. дис. ... канд. юрид. наук : 12.00.03 / А. Б. Савельев. - М., 2003. - 30 с.

18. Ламм Т. В. Многосторонние договоры в гражданском праве : автореф. дис. ... канд. юрид. наук : 12.00.03 / Т. В. Ламм. - Иркутск, 2003. - 30 с.

19. Романец Ю. В. Система договоров в гражданском праве России: монография / Ю. В. Романец. - М. : Норма, 2013. - 496 с.

\section{References}

1. Alekseev S. S. Obshchie dozvoleniya i zaprety $v$ sovetskom prave [General permits and prohibitions in Soviet law]. Moscow, Yuridicheskaya literatura Publ., 1989. 288 p.

\section{Baikal Research Journal}


2. Rublev V. V. Concept and legal characteristic of shareholders' agreement as a civil-legal agreement regulated by Russia's civil legislation. Sovremennoe pravo = Modern Law, 2010, no. 9, pp. 102-109. (In Russian).

3. Sergeev A. P. Legal nature and use of shareholders' agreements according to Russian law. Korporativnyi yurist $=$ Corporative Lawyer, 2007, no. 10, pp. 6-10. (In Russian).

4. Lomovskii S. A. The new in legal regulation of shareholders' agreements in Russian legislation. Zakonodatel'stvo = Legislation, 2010, no. 5, pp. 34-39. (In Russian).

5. Andreev V. K., Laptev V. A. Korporativnoe pravo sovremennoi Rossii [Corporative law of present-day Russia]. Moscow, Prospekt Publ., 2016. 240 p.

6. Laptev V. A. Corporative agreement in system of regulation resources for corporate relations. Predprinimatel'skoe pravo = Business Law, 2016, no. 1, pp. 23-31. (In Russian).

7. Shitkina I. S. Shareholders' agreement (contracts on implementing participants' rights) as a resource of regulating corporate relations. Khozyaistvo i pravo = Economy and Law, 2011, no. 2, pp. 36-47. (In Russian).

8. Bychkov A. I. Cases when shareholders' agreement is a mixed contract. Advokatskaya praktika = Legal Practice, 2011, no. 5, pp. 40-43. (In Russian).

9. Borodkin V. G. Subject and content of corporate agreement in Russia foreign systems of justice. Pravo i ekonomika = Law and Economy, 2014, no. 2, pp. 39-44. (In Russian).

10. Gongalo B. M. Uchenie ob obespechenii obyazatel'stv. Voprosy teorii i praktiki [Doctrine of securing obligations. Issues of Theory and Practice]. Moscow, Statut Publ., 2004. 222 p.

11. Braginskii M. I., Vitryanskii V. V. Dogovornoe pravo. Obshchie polozheniya [Contract Law. General provisions]. 3nd ed. Moscow, Statut Publ., 2001. 848 p.

12. Suvorov E. D. Agreement on corporate right implementation. Vestnik Vysshego Arbitrazhnogo Suda $R F=$ Bulletin of Supreme Arbitrary Court of the Russian Federation, 2011, no. 10, pp. 44-72. (In Russian).

13. Vitryanskii V. V. System of civil-legal agreements in terms of reforming civil legislation. Vestnik Vysshego Arbitrazhnogo Suda $R F=$ Bulletin of Supreme Arbitrary Court of the Russian Federation, 2012, no. 1, pp. 26-59. (In Russian).

14. Gureev V. A. Problemy zashchity prav i interesov aktsionerov $v$ RF. Avtoref. Kand. Diss. [Problems of defending shareholders' rights and interests in the Russian Federation. Cand. Diss. Thesis]. Moscow, 2007. 28 p.

15. Shmelev R. V. Corporate agreement in Civil Law of the Russian Federation. Available at: http://www.consultant.ru. (In Russian).

16. Stepanov D. I., Fogel' V. A., Shramm Kh.-I. Corporate agreement: approaches of Russian and German law to specific issues of regulation. Vestnik Vysshego Arbitrazhnogo Suda $R F=$ Bulletin of Supreme Arbitrary Court of the Russian Federation, 2012, no. 10, pp. 22-69. (In Russian).

17. Savel'ev A. B. Dogovor prostogo tovarishchestva v rossiiskom grazhdanskom prave. Avtoref. Kand. Diss. [Single partnership agreement in Russian Civil Law. Cand. Diss. Thesis]. Moscow, 2003. $30 \mathrm{p}$.

18. Lamm T. V. Mnogostoronnie dogovory $v$ grazhdanskom prave. Avtoref. Kand. Diss. [Multipartite agreements in civil law. Cand. Diss. Thesis]. Irkutsk, 2003. 30 p.

19. Romanets Yu. V. Sistema dogovorov $v$ grazhdanskom prave Rossii [System of agreements in Russia's Civil Law]. Moscow. Norma Publ., 2013. 496 p.

\section{Информация об авторе}

Гребенюк Мария Андреевна - аспирант, кафедра предпринимательского и финансового права, Байкальский государственный университет, 664003, г. Иркутск, ул. Ленина, 11, e-mail: magnit333@list.ru.

\section{Author}

Maria A. Grebenjuk - PhD Student, Chair of Business and Financial Law, Baikal State University, 11 Lenin St., 664003, Irkutsk; e-mail: magnit333@list.ru.

\section{Baikal Research Journal}


Для цитирования

Гребенюк М. А. О правовой природе корпоративного договора / М. А. Гребенюк // Baikal Research Journal. - 2017. — T. 8, № 3. — DOI : 10.17150/2411-6262.2017.8(3).23.

\section{For Citation}

Grebenyuk M. A. On legal essence of corporate contract. Baikal Research Journal, 2017, vol. 8, no. 3. DOI: 10.17150/2411-6262.2017.8(3).23. (In Russian).

\section{Baikal Research Journal}

